\title{
Goa: uma identidade diferente da indiana justificaria a condição colonial?
}

Eduardo de Almeida Navarro

Universidade de São Paulo

RESUMO: EM DEZEMBRO DE 1961, AS FORÇAS ARMADAS DA UNIÃO INDIANA INVADIRAM OS TERRITÓRIOS COLONIAIS PORTUGUESES DE GOA, DAMÃO E DIU. O IMPÉRIO ULTRAMARINO PORTUGUÊS COMEÇAVA A DESMORONAR. DEPOIS DISSO, COMEÇARIA A GUERRILHA NA ÁFRICA PORTUGUESA, O QUE LEVARIA À INDEPENDÊNCIA DE VÁRIOS PAÍSES LUSÓFONOS. GOA PODERIA TER SIDO MAIS UM PAÍS LUSÓFONO INDEPENDENTE, EM VEZ DE TER-SE INTEGRADO NA ÍNDIA? O PRESENTE ARTIGO DISCUTE ESSA QUESTÃO.

ABSTRACT: IN DECEMBER 1961, INDIAN UNION MILITARY FORCES INVADED THE PORTUGUESE COLONIES IN GOA, DAMAN AND DIU. THE PORTUGUESE SEABWORNE EMPIRE BEGAN TO COME DOWN. AFTER THAT, THE GUERRILLAS IN THE AFRICAN COLONIES WOULD LEAD TO THE INDEPENDENCE OF MANY PORTUGUESE SPEAKING COUNTRIES. COULD GOA HAVE BEEN ANOTHER INDEPENDENT COUNTRY, INSTEAD OF BEING INTEGRATED IN INDIA? THIS PAPER DISCUSSES THIS MATTER.

PALAVRAS-CHAVES: GOA; ÍNDIA; DESCOLONIZAÇÃO; LUSOFONIA KEYWORDS: GOA; INDIA; DECOLONIZATION; PORTUGUESE LANGUAGE 
om a independência da Índia do Império Britânico em 1947, criava-se o "problema de Goa". Como Portugal poderia continuar a manter colônias no subcontinente indiano no contexto do processo de descolonização do pósguerra? Uma justificativa para a manutenção das colônias portuguesas ali era, segundo o ditador português Salazar, o fato de que Goa, Damão e Diu eram a expressão de Portugal na Índia, isto é, tinham uma identidade própria. Segundo ele, numa de suas manifestações a respeito, a Índia portuguesa tinha uma mentalidade, uma visão da vida e uma atmosfera espiritual próprias. Nenhum viajante qualificado que passasse em Goa, saindo da União Indiana, poderia deixar de ter a impressão de que estava entrando numa terra inteiramente diferente. Ainda segundo suas palavras, a maneira pela qual as pessoas pensavam, sentiam ou agiam era europeia. Pode não haver nenhuma fronteira geográfica ou econômica, mas haveria, indubitavelmente, uma fronteira humana: Goa seria uma transplantação do Ocidente em terras do Oriente. ${ }^{1}$

Mas, segundo os inimigos dos portugueses, aninhados em torno do movimento "Combatentes da Liberdade", Goa, Damão e Diu não passavam de terras da Índia ocupadas havia séculos, sem identidade diferente da indiana. Com efeito, argumentavam eles que a língua portuguesa não tinha conseguido ao longo dos quatro séculos e meio de dominação lusa tornar-se majoritária naqueles territórios. Ao contrário, era falada por menos de cinco por cento dos seus habitantes. Com relação à religião, em 1961 o número de hindus superava muito o de cristãos, representando $59,92 \%$ do total da população, ao passo que os cristãos correspondiam a 38,07\%. ${ }^{2}$

\section{A tomada de Goa, Damão e Diu pelos indianos em 1961 e seus antecedentes}

A profunda divisão ideológica ocorrida em torno da descolonização da Índia portuguesa deixou suas marcas no corpo da linguagem. Para um católico lusófono e adepto de Portugal seria "ocupação" e, para os entusiastas da soberania indiana sobre aquelas terras, seria a Libertação.

1. Sinha, A., Goa Indica, p. 19.

2. Statistical Pocket Books of Govt. Of Goa. em Angle, P. S. Goa, Concepts and Misconcepts, 2005. 
Os sinais de uma anexação dos territórios portugueses pela Índia havia muito já eram dados. Com o final da Segunda Guerra Mundial, as potências coloniais da Europa saíam enfraquecidas e a descolonização estaria em curso por toda a parte. $\mathrm{Na}$ África iniciam-se os movimentos nacionalistas em Angola e a luta indiana por Goa, Damão e Diu era observada atentamente pelos líderes de tais movimentos. Com efeito, o Brasil, o Ceilão e outros territórios já haviam sido perdidos em outros séculos, mas, no século XX, as colônias da Índia seriam as primeiras que sairiam da dominação portuguesa e isso se revestia de importante significado simbólico: ali estaria o início do fim do império português no mundo e a palavra de ordem para que a guerrilha na África começasse. Salazar, contudo, mantinha-se intransigente e não percebia o quadro desfavorável para a manutenção de colônias naquele subcontinente.

Salazar governava Portugal com mão de ferro desde 1928. Portugal seria o país mais tradicionalista da Europa ocidental: exibia uma economia predominantemente rural, uma cultura fortemente religiosa, onde o Padroado seria reinstituído e a Igreja apoiada oficialmente. Segundo Maxwell (2006, p.36), com Salazar, Portugal voltou as costas para o século XX.

De 1947 a 1961, Nehru tentou negociar pacificamente a passagem de Goa, Damão e Diu para Índia. Em 1955, a Índia recém-independente resolveu impor um embargo econômico sobre as colônias portuguesas ao lado de seu território. Contudo, em virtude do aquecimento econômico de Goa com a descoberta de grandes jazidas de minério de ferro e de sua exportação, Portugal passou a abastecer seus territórios na Índia, realizando comércio com o vizinho Paquistão, país independente. Em 15 de agosto de 1956, os satyagrahis, militantes da resistência pacífica hindu, tentaram invadir Goa, tendo sido derrotados, dessa feita, pelo exército português.

Com a saída dos ingleses da Índia, Portugal perdia seu histórico aliado, que poderia garantir sua permanência ali. Foi a primeira nação europeia a criar colônias na Índia e seria a última a sair dela. Com efeito, a questão seria finalmente resolvida por meio das armas alguns anos depois.

Assim, na madrugada de 18 de dezembro de 1961, o exército indiano atacou Goa, Damão e Diu. Goa foi cercada de todos os lados, inclusive por mar, e a força aérea indiana realizou bombardeios com aviões a jato sobre seu território. O último governador português, Vassalo e Silva, capitulou no dia 19 
de dezembro. Somente em Damão e Diu houve mais resistência: em Damão ela durou trinta e seis horas.

Quem apoiaria a dita Libertação? Sem dúvida alguma a imensa massa de hindus, para os quais o domínio português não interessava absolutamente. Ainda era viva a memória das perseguições religiosas do passado, eram fortes os ressentimentos contra a elite cristã privilegiada que tinha, durante o governo colonial português, as posições de prestígio e os melhores salários. Além disso, era conhecida a fragilidade econômica de Portugal e a pouca disponibilidade de recursos do país para investir em suas colônias indianas. Mas também eram diversos os cristãos lusófonos que apoiaram a Libertação. Para eles, a saída dos portugueses da Índia poderia significar a ocupação de posições-chave na política e na economia, principalmente no território de Goa, para o qual tais elites projetavam uma condição de Estado dentro da União Indiana. Já Damão e Diu, dadas as suas pequenas dimensões, não poderiam aspirar a tal prerrogativa, e permanecem como territórios nacionais desde a anexação em 1961.

Assim, em 19 de dezembro de 1961, encerrava-se um período de 451 anos de colonização portuguesa na Índia.

\section{O período pós-colonial de Goa, Damão e Diu e as consequências polí- ticas e sociais do fim da Índia portuguesa}

Salazar tentou reverter a situação por meio da arbitragem da Corte Internacional de Haia, mas o voto da União Soviética no Conselho de Segurança da ONU foi-lhe desfavorável.

Um novo momento histórico abre-se, então, para o último império colonial do mundo. A perda das suas colônias indianas levaria Portugal a começar a enfrentar as guerrilhas na África. Com efeito, Angola, Moçambique, São Tomé e Príncipe, Guiné-Bissau e Cabo Verde ainda não se haviam tornado independentes e conter os movimentos de independência seria, então, o grande desafio para Portugal. Imensos recursos econômicos e humanos foram voltados para o combate a tais movimentos. Esse seria um dos fatores que desencadeariam a Revolução dos Cravos, em 1974, quando caiu o regime salazarista e Marcello Caetano é deposto por um golpe militar. 
Salazar não aceitou abrir mão das colônias portuguesas na Índia, assim como fez a França em 1956 com relação a suas colônias no país, como Pondicherry, por exemplo. Com isso, por meio de acordos diplomáticos, a língua francesa continuou a ser estudada nas escolas, a ser usada em programas de rádio, nos jornais e nas igrejas, ao passo que a ocupação de Goa, Damão e Diu pela Índia acarretaria a eliminação do português como matéria obrigatória na escola primária e nos liceus e sua exclusão dos meios de comunicação de massa.

Com a Libertação, as posições acerca do status político das ex-colônias na grande Índia dividem-se, principalmente em Goa, território maior e mais próspero que Damão e Diu. Houve a tentativa de anexar Goa ao estado do Maharashtra, onde se situa Bombaim, principalmente por parte de partidos e movimentos hinduístas interessados em varrer as influências portuguesas ainda muito presentes e fortes naquela ex-colônia. A principal voz em favor da fusão era a de Dayanand Bandodkar. Uma Goa anexada ao estado do Maharashtra veria sua cultura tradicional diluir-se rapidamente na cultura indiana hinduísta. Por outro lado, afirmar uma identidade goesa própria, diferente da indiana, implicaria aceitar um estado a mais no país. Isso foi o que defenderam as elites cristãs e certas facções hinduístas, preocupadas com a perda de seu poder, que a fusão com o estado do Maharashtra acarretaria. No caso dos cristãos, minoria em Goa, eles se veriam como um copo d'água em meio a um mar de hindus, totalmente destituídos do poder e das posições de prestígio de que gozavam no período colonial.

Afirmar que a identidade goesa estava na arquitetura lusitana ali existente, na língua portuguesa ali falada, no carnaval ali festejado era dar argumentos ao inimigo, uma vez que essa identidade provinha do colonizador europeu cujas marcas muitos queriam ver apagadas ou não viam como predominantes. Para eles, a real identidade goesa não era a identidade cristã, mas, sim, a identidade indiana. Para eles, a larga maioria dos goeses não era culturalmente diferente dos outros indianos. Era preciso, assim, encontrar uma identidade verdadeiramente indiana para Goa. Ela foi encontrada na língua concani, ali é falada. O concani é uma língua indo-ariana, falada não somente em Goa, mas também em algumas partes da costa leste, inclusive no Malabar (ou Kerala), que é a região onde está Cochim.

Assim, foi nessa língua que se buscou a autêntica face indiana de Goa, o que a distinguia do Maharashtra e não justificava uma fusão com esse estado 
indiano. Mas o concani de Goa era escrito, nos meios cristãos, com o alfabeto latino, ao passo que nos meios hindus em devanágari, alfabeto composto de 48 letras escritas da esquerda para a direita, utilizado na escrita do sânscrito, do híndi, e de outras línguas da Índia. Isso foi um ponto de conflito entre os setores cristãos e os hindus que partilhavam a ideia de estado autônomo para Goa.

Curiosamente, o maior defensor de uma identidade goesa foi o primeiro-ministro Jawaharlal Nehru, um dos pais da Índia independente. Em maio de 1963 ele visitou Goa pela primeira vez e afirmava num encontro público em Panjim:

Goa tem uma personalidade distinta e nós a reconhecemos. Será uma pena destruir aquela individualidade e nós decidimos mantê-la. Com o influxo do tempo uma mudança poderia vir. Mas ela será gradual e será feita pelos próprios goeses. Nós decidimos preservar a identidade separada de Goa na União Indiana e nós nos atemos firmemente a ela...

Num encontro público em Margão, outra cidade de Goa, no dia seguinte, ao lhe pedirem para mencionar alguns dos aspectos distintivos da individualidade goesa, Nehru disse:

Ela é realmente mais sentida que descrita. Você sente que um Andhra é diferente de um Rajput. Você sente que um negro é diferente de um europeu. Você sente que um brasileiro não é o mesmo que um nova-iorquino. (...) Os goeses (...) são europeizados, sua arquitetura, seus costumes sociais, suas formas de cumprimento foram influenciadas. Mas tudo isso não precisa levar ao conflito. Pode haver e tem havido unidade na diversidade e os goeses serão tão indianos quanto os maratas ou os bengalis, apesar do impacto dos portugueses sobre sua cultura. Nós somente precisamos ter a necessária atitude de acomodação e de simpatia para ver tudo isso. ${ }^{4}$ (SINHA, 2002, p. 41-42)

3. Goa has a distinct personality and we have recognized it. It will be a pity to destroy that individuality and we have decided to maintain it. With the influx of time, a change might come. But it will be gradual and will be made by Goans themselves. We have decided to preserve the separate identity of Goa in the Union of India and we hold to it firmly. (in Sinha, 2002, p. 41)

4. It is really more felt than described. You do feel that an Andhra is different from a Rajput. You do feel that a Negro is different from a European. You do feel that a Brazilian is not the same as a New Yorker. (...) Goans (...) are Europeanized, their architecture, social customs, forms of greeting have been influenced. But all this need not lead to conflict. There can be and has been unity in diversity and Goans will be as much Indians as the Marathas or Bengalis, despite the 
Houve muita resistência entre os hindus em aceitar essa posição de Nehru, que teria como consequência inevitável, se ela fosse mantida, a criação do estado de Goa, separado de outros estados indianos. Alguns deles, como A. K. Priolkar, argumentavam que Nehru desconhecia os fatos históricos, considerando Goa um todo homogêneo. Na verdade, dizia ele, Goa constituía-se das Velhas Conquistas, fortemente lusitanizadas, e das Novas Conquistas, que passaram para o domínio de Portugal somente no século XVIII e onde a presença da cultura hindu era maciça. Assim, como considerar uma "identidade goesa" sem levar em conta que Goa é composta de distritos culturalmente diferenciados?

$\mathrm{Na}$ verdade, Nehru buscava não criar entre população cristã de Goa focos de resistência política à passagem da ex-colônia portuguesa para o governo da Índia, inclusive ações terroristas. Ele desejava manter Goa, Damão e Diu como territórios nacionais até que a transição fosse perfeitamente assimilada e, então, discutir a situação de Goa dentro da União Indiana. Em Damão e Diu estava fora de cogitação a busca pela condição de estados autônomos, dados seus pequenos territórios.

Depois de amplo debate no parlamento indiano, que consumiria alguns anos, durante os quais morreria o primeiro-ministro Nehru, foi marcado um referendo popular para 16 de janeiro de 1967, no qual o povo goês decidiria o status político do território: ou fusão com estado do Maharashtra ou condição de estado autônomo. A ideia da fusão com o outro estado foi rejeitada por $54,20 \%$ dos votos. Goa seria o $25^{\circ}$ estado da Índia.

Com o fim do Estado colonial, Goa, Damão e Diu foram afetados por migrações de indianos provenientes de outras partes do país. Em Goa isso produziria reações por parte dos seus habitantes, ressentidos por verem suas oportunidades de trabalho diminuídas pelo afluxo de tanta gente de fora, que não falava concani nem marata, línguas compreendidas e faladas naquele estado. Para a população cristã mais tradicional e ainda falante do português, isso significava sua diluição ainda maior num mar de hindus, provocando perda de valores culturais característicos da identidade goesa, na perspectiva daquela comunidade cristã. 


\section{Goa poderia ter-se convertido num país independente?}

As ex-colônias portuguesas na Índia vivenciaram uma situação histórica muito diferente da dosoutros antigos territórios coloniais portugueses, como o Brasil, Moçambique ou Cabo Verde, por exemplo. Esses países deixaram a condição colonial, tornando-se independentes. No caso de Goa, Damão e Diu, houve anexação de seus territórios a um país maior ao qual haviam pertencido havia mais de quatro séculos. Diante dessa situação, muitos que visitam Goa se perguntam por que tal território não buscou tornar-se um país independente.

Com efeito, foi em Goa que houve pela primeira vez, no século XVIII, em pleno período colonial, um movimento de emancipação política, a Conspiração dos Pintos, a segunda revolta anticolonial na história moderna, ocorrida quatorze anos depois da Boston Tea Party (1773), que levaria ao início das revoltas entre as colônias americanas e à Guerra de Independência dos Estados Unidos. A Conspiração dos Pintos ocorreu em 1787, portanto dois anos antes da Inconfidência Mineira do Brasil. O mundo estava, com efeito, sob o influxo das ideias iluministas e das novas formulações burguesas acerca do homem e da sociedade e as elites coloniais, tanto de Goa quanto das Minas Gerais; no Brasil, inebriaram-se delas em seus movimentos de emancipação.

A Revolta de 1787 em Goa tinha claramente o propósito de tornar independente aquela colônia de Portugal. Ela começou entre padres católicos goeses que estavam insatisfeitos com os portugueses por não conseguirem, na sua condição de indianos, promoções na hierarquia católica. Estes associaram-se a oficiais militares goeses que, pela mesma razão, isto é, por sua condição de indianos, não conseguiram ascender na carreira militar. Os cabeças da conspiração foram dois eruditos padres católicos, Caetano Francisco Couto, de Panjim, e José Antônio Gonçalves, de Divar. Esses sacerdotes tinham aspirações de se tornarem bispos e, por verem bloqueadas suas pretensões, foram pessoalmente a Portugal para ter audiência com o rei para que ele interferisse nessa questão. Vendo frustrados seus projetos, os dois padres dirigiram-se a Paris, convulsionada pela Revolução Francesa, onde vivia o famoso Abade Faria, um goês ilustre cujo nome completo era José Custódio Faria, proveniente de Candolim. É importante, antes de prosseguirmos, conhecermos melhor a vida e a obra desse que foi um dos mais famosos goeses da História. 
Nascido em 1756, logo ficariam conhecidos seus magníficos dotes intelectuais e aguda inteligência, que o fariam estudar na Europa desde a adolescência. Tendo-se decidido a tornar-se sacerdote, foi levado por seu pai, Caetano Valeriano Faria, para Portugal, aos quinze anos de idade, donde logo segue para Roma para ali realizar seus estudos eclesiásticos. Tendo sido ordenado sacerdote em 1780, doutorou-se na Universidade de Roma em Filosofia e Teologia e, então, voltou a Portugal, onde se distinguiu pelas virtudes morais e intelectuais, conquistando fama de grande pregador. Mas foi por outra razão que seu nome passaria à História: o Abade Faria foi o criador da hipnose, que estudaria e praticaria por longos anos.

Em 1788, às vésperas da Revolução Francesa, ele emigra para Paris e ali ele se envolve com altas personalidades políticas, tendo assumido a chefia de um dos batalhões revolucionários, participando inclusive da tomada da Bastilha, no ano seguinte. Na França pós-revolucionária, ele publicaria em 1819 Da Causa do Sono Lúcido no Estudo da Natureza do Homem, que intrigaria a ciência médica da época, criando fortes e intermináveis polêmicas. Ele morreria em Paris nesse mesmo ano de 1819, pobre e abandonado. Seu nome foi imortalizado pela obra de Alexandre Dumas, O Conde de Monte Cristo, em que é um dos personagens, exatamente aquele que mostra a Edmund Dantes o tesouro de Monte Cristo.

Ao chegarem a Paris os padres goeses Caetano Francisco Couto e José Antônio Gonçalves, às vésperas da Revolução Francesa, foram aconselhados pelo Abade Faria a encabeçarem uma conspiração em Goa com o objetivo de obter a independência política e o fim do domínio português na Índia. Dizia-se que os padres sediciosos teriam o apoio do governo revolucionário da França, que, a instâncias do Abade Faria, bem relacionado com figuras eminentes da Revolução Francesa, enviaria navios em ajuda aos conspiradores goeses. Também se diz que o sultão de Tipu também apoiava o movimento. Esse sultão, segundo Rivara (1996, p. 36), crescia em poder e ameaçava o domínio português na Índia.

Em Goa e também em Portugal havia muitos padres e alguns oficiais do exército que estavam a seu lado. A família Pinto de Candolim havia oferecido apoio financeiro para o movimento e diversos membros dela envolveram-se nele, razão pela qual a Revolta de 1787 ficou também conhecida na história como a Conspiração dos Pintos. 
O dia para o levante estava marcado: 10 de agosto. Houve, porém, vazamento de informações, que chegaram aos ouvidos do governador de Goa, Francisco da Cunha e Menezes. O clerk da comunidade de Aldona, Antônio Eugênio Toscano, fora pessoalmente comunicar o governador a respeito do que estava sendo planejado contra o governo português de Goa, que mandou prender quarenta e sete pessoas envolvidas, entre as quais dezessete padres e sete oficiais do exército. O movimento foi sufocado, da mesma maneira como foi a Inconfidência Mineira no Brasil.

Em 9 de dezembro de 1788 vieram as sentenças: várias condenações à morte na forca, deportações para Angola, Moçambique, Bengala e outros lugares, e também condenações às galés. Frustrava-se o primeiro movimento de independência dentro do império português.

A Revolta de 1787 foi conduzida pelas elites goesas, totalmente à margem das massas populares, exatamente como foi a Inconfidência de Minas.

Em entrevista recente dada ao jornal Expresso (edição 1787) de Portugal, o ex-presidente português Ramalho Eanes defendeu a ideia de que Goa era um caso único no espaço colonial português e que tinha todas as condições para se firmar como país independente. Nessa entrevista ele disse:

Goa era um microcosmos histórico e político muito distinto e distintivo. Para ser um estado de fato, só lhe faltava o poder político. Todas as grandes funções eram exercidas por goeses - só o governador e o comandante militar não o eram. $\mathrm{O}$ meu comandante e o $2^{\circ}$ comandante de companhia eram goeses. A administração, mesmo a superior, era goesa, os juízes dos tribunais supremos eram goeses; a escola médico-cirúrgica era dirigida por goeses...

(...) Tínhamos realizado ali uma coisa que, como depois tive a ocasião de constatar, não realizamos em mais parte nenhuma. Criou-se uma cultura que não era a nossa, mas que não era a indiana. Goa tinha uma personalidade cultural própria. Recentemente, o professor Fausto Quadros comparou Goa a Timor; acho que tem uma certa razão. Aquilo que poderia ter sido, não o Estado Português da Índia, mas o Estado de Goa.

(...) Salazar, depois da II Guerra Mundial, teve todas as condições para conceder a independência de Goa. Responsabilizo inteiramente Salazar por não ter sido capaz de ler a situação geopolítica determinada pelo fim da II Guerra Mundial, em que as colônias não tinham cabimento. Salazar não percebeu isso 
e acabou por nos condenar à descolonização inglória que produzimos. É o primeiro e grande responsável por isso.

Várias vezes me perguntaram em Goa o que pensava sobre o futuro. Jovem tenente, convencido ainda que Portugal ia do Minho até Timor, que podia ser um exemplo no mundo, disse-lhes que Portugal estava para ficar e que eles eram tão portugueses como eu. Quando se deu a invasão, entendi que, embora sem mentir, os tinha enganado - e que o mínimo que podia fazer era oferecer-me como voluntário.

Perguntado acerca de Macau, se seria possível àquele território português na China ter sido independente, Eanes disse:

Nunca. Macau era realmente um território chinês. Enquanto em Goa havia uma elite, que não era portuguesa, mas também não era indiana - era goesa - em Macau havia chineses e portugueses. Em Goa, Afonso de Albuquerque determinou o casamento de nobres indianas com os portugueses, ... o que demonstra que nós, no fundo não somos racistas. (...) A Carta de Pero Vaz de Caminha é uma maravilha; ali não se diz que encontramos uns tipos escuros e despidos; ele só consegue ver o que eles têm de belo e de diferente em termos culturais. Um indivíduo culturalmente racista tem um outro olhar - não tem aquele olhar. Uma das minhas grandes decepções ao chegar (a Macau) foi ver que, afinal, o modelo de Goa não era o nosso modelo. ${ }^{5}$

\section{Após a anexação de Goa, Damão e Diu à Índia: que resta da cultura e das instituições de matrizes lusitanas naquele país?}

Para os indianos em geral, a incorporação dos territórios portugueses na Índia ao território desse país, tornado independente em 1947, significava o retorno a uma situação original, à volta deles à "mãe Índia", da qual haviam sido subtraídos havia quatro séculos e meio. Alguns, como o escritor goês Sinha (2002, p. 209) regozijam-se com o esvaecimento das influências coloniais. No entanto, se a língua portuguesa na Índia perde terreno gradativamente,

5. Expresso, 20 de fevereiro de 2007. 
uma outra língua de antigos colonizadores, o inglês, aumenta dia a dia sua influência no país. Por que um país de culturas milenares como a Índia, com línguas autóctones em que se vazou uma riquíssima literatura, como o sânscrito, o híndi e o bengali, por exemplo, não buscou enfraquecer também o domínio do inglês no país após sua independência? Na verdade, o argumento econômico pesa muito mais que considerações de natureza cultural e afetiva. Se Portugal tivesse atingido posição econômica de proa como a Inglaterra, o destino de nossa língua na Índia certamente seria outro.

Com efeito, o recente ingresso de Portugal na Comunidade Econômica Europeia tem dado a alguns a esperança de um reavivamento da língua portuguesa naquele país extremamente populoso. Com efeito, poucas são as famílias de classe média naquele país que não tenham algum de seus membros no exterior, principalmente no Golfo Pérsico, o destino mais próximo, mas também na Europa e nos Estados Unidos. A diáspora indiana começou, com efeito, há mais de dois séculos. Obter um passaporte português significa, hoje, para muitos goeses, damanenses e diuenses, o ingresso na Comunidade Europeia, e principalmente a possibilidade de ir para Londres, onde há uma verdadeira colônia de indianos provenientes da antiga Índia portuguesa. Mas obter passaporte português implica falar a língua portuguesa, que hoje muitos estudam com esse objetivo bem pragmático. Nada de estudos literários ou filológicos da língua de Camões...

Com a criação da Universidade de Goa, em 1975, foi instituído o departamento de português naquela instituição. Mas poucos resultados práticos tem obtido no que diz respeito à diminuição dos falantes de português naquele estado.

A Fundação Oriente, sediada em Lisboa, é uma instituição privada portuguesa que busca apoiar projetos e iniciativas de caráter cultural, artístico, educacional, filantrópico e social, visando a manter e a fortalecer os elos históricos e culturais entre Portugal e países asiáticos de antiga colonização lusitana, como a China, o Timor Leste e a Índia. Para tanto, ela mantém delegações em tais países. No bairro de Fontainhas, repleto de antigos casarões portugueses, está sua sede em Goa, uma bela construção em estilo luso-indiano. Uma de suas ações na Índia é a manutenção de cursos de língua portuguesa em escolas de Goa, Damão e Diu. No entanto, sem um suporte estatal, tal como o que existia até 1961, o português restringe-se a ocupar a posição de 
matéria optativa no currículo escolar. Além disso, seu estudo hoje é como o de qualquer outra língua estrangeira, como um copo d'água em meio a um mar de falantes de inglês ou de línguas indianas.

\section{Referências Bibliográficas}

ANGLE, Prabhakar Angle. Goa, Concepts and Misconcepts. Mumbai: The Goa Hindu Association, 2005.

ANTHONY, Philomena Sequeira. The Goa-Babia Intra Colonial Relations (1675-1825). Tellicherry: Irish, 2004.

. Colonial Brazil and Goa: Visible and Invisible Links. In: Journal of the Directorate of Archives, Archaelogy and Museum. Goa: vol. VIII, 1990, p. 89.

BARroS, João de. Décadas de Ásia, Lisboa: 1945-1946, 4 Vols.

BORGES, Charles J. Goa and the Revolt of 1787. Nova Delhi: Concept Publishing Company, n. 6, 1996.

Goa to me. Nova Delhi: Concept Publishing Company, 1994.

BOXER, C. R. The Tragic History of the Sea. Cambridge: Univ. Press, 1959. 2002.

O Império Marítimo Português - 1415 - 1825. São Paulo: Companhia das Letras,

BRITTTO, Nougueiro de. Caravelas, Naus, e Galés de Portugal. Porto: Livraria Lello, 1965.

CASTANHEDA, Fernão Lopes de. História do Descobrimento e Conquista da Índia pelos Portugueses. Coimbra: 1924-1933.

CASTANHEIRA, José Pedro, Ramalho Eanes: «Goa poderia ter sido independente». Entrevista para o jornal Expresso, n. 1787, 20 fev. 2007. Disponíel em: <www. supergoa.com. >. Acesso em: 30//011/2010

CHACON, Vamireh. Goa e Macau: diário de uma viagem aos confins da luso-tropicalidade. Rio de Janeiro: Editora Civilização Brasileira, 1995.

DALGADO, Sebastião Rodolfo. Glossário Luso-Asiático. Nova Delhi / Madras: Asian Educational Services, 1988, 2 vols.

FREIRE, Gilberto. Aventura e Rotina: sugestões de uma viagem à procura das constantes portuguesas de caráter e ação. Rio de Janeiro: José Olympio, n. 77, 1953. (Coleção Documentos Brasileiros).

GOMES, Olivinho J. F. Goa. Nova Delhi: National Book Trust, 2002.

MAXWELL, Kenneth. O Império Derrotado - Revolução e Democracia em Portugal. São Paulo: Companhia das Letras, 2006.

MORAIS, Carlos A. de. A Queda da Índia portuguesa. Braga-Lisboa: Intervenção, 1980. 
PEARSON, M. N. Coastal Western Índia. Nova Delhi: Concept Publishing Company, 1981.

RIVARA, Joaquim Heliodoro da Cunha Rivara. Goa and the Revolt of 1787. Nova Delhi: Concept Publishing Company, Xavier Centre of Historical Research Series, n. 6, 1996.

RODRIGUES, Maria de Lourdes Bravo da Costa. Éditions Karthala: The Status of Portuguese Language and some other Cultural Aspects in Goa. In: Lusophonies Asiatiques, Asiatiques en Lusophonies / Lusotopie. 2000.

SANCEU, Elaine. Caminho da Índia.2. ed. Porto: Livraria Civilização, 1958.

SILVA REGO, António de. Documentação para a História das Missões da Padroado Português no Oriente. Lisboa: 1950-1955.

SINHA, Arun. Goa Indica - a Critical Portrait of Postcolonial Goa. Nova Delhi: Bibliophile South Asia / Promilla \& Co. Publishers, 2002.

SOUZA, Teotônio R. de (Org.). Discoveries, Missionary Expansion and Asian Cultures. Nova Delhi: Concept Publishing Company, 1994.

VELHO, Selma. Goa - Sintese Cultural Indo-Portuguesa? Lisboa: II Seminário Internacional de História Indo-Portuguesa, 1980.

Recebido em 07/03/2011 e aprovado em 29/03/2011. 